\title{
European Association for American Studies A Gentlemen's Club or a Scholar's Organization?
}

It is well-known that interest in the USA has grown during the post-war years. This has been most noticeable in the coverage of American Society by the mass media but even on a more popular-scientific plane an increased interest in America can be observed. Without a doubt research has also shown an increased interest in a more systematic analysis of the different aspects of the development of American society. Because of the wide scope of the subject matter researchers involved in the field of American Studies are located at universities throughout Europe and the need for contact and an exchange of information has become necessary. Traditionally, this problem has been solved by the organization of international conferences. In this special case it has also been possible to exchange ideas and research results by visiting the USA and its research milieu. It is of course worthwhile to organize all of these contact possibilities on a more permanent basis. This has also occurred through the European Association for American Studies and through different national organizations of the same type as NAAS. We who are involved in these organizations have reason to question whether or not these organizations fulfill the expectations placed on them concerning contacts in research and educational areas.

A quick look at the above mentioned organizations reveals that they are completely supported and controlled by olderly established researchers and prominent university scholars. Their mean age is quite high. Such organizations "automatically" create contact problems with younger researchers with the result that the most interesting research in the future will in only a very small way be reflected in the organizations' conferences, periodicals, etc. This situation is even more serious in an area such as American Studies where the numerous types of research are influenced by different political opinions. It should, therefore, not surprise anyone that so little critical research is or will be reflected in for example the European Association's activities. It is hardly any exaggeration to say that because of this the younger university scholars feel alienated and fairly indifferent toward EAAS's activities. The possibility of influencing these organizations scarcely exists for their executive committees are selected through cooptation.

It would not be completely fair to direct an isolated criticism against organizations within the field of American Studies. The above mentioned tendencies concerning international conferences and the exchange of research results can also be observed in many other subject areas. But this is no defense for why these organizations function as they do. We must 
now actively work to make use of those possibilities which exist to bring about an effective exchange of research results on an international level and to develop a contact between the older and younger researchers and between university scholars and school teachers.

If these formal organizations can function in this way it would be excellent. On the other hand if they are unable to do so, maybe there are no reasons to keep them alive with artificial respiration.

This issue of our journal is devoted to the research debate concerning the role of the transport sector during the period of mass emigration to the USA and Canada. Kristian Hvidt has earlier presented research results on this subject in his dissertation Flugten til Amerika eller Drivkræfter 'i masseudvandringen fra Danmark 18681914 (Escape to America or Mass Emigration from Denmark 18681914). Berit Brattne has recently defended a dissertation in Uppsala on the activities of emigrant agents during the 1880 s.

Sune Akerman 